\title{
Retraction Note: Neural network-based urban rainfall trend estimation and adolescent anxiety management
}

\author{
Mengjiao Liang ${ }^{1}$
}

Published online: 3 November 2021

C) Saudi Society for Geosciences 2021

Retraction Note to: Arabian Journal of Geosciences (2021) 14: 1070 https://doi.org/10.1007/s12517-021-07246-5

The Editor-in-Chief and the Publisher have retracted this article because the content of this article is nonsensical. The peer review process was not carried out in accordance with the Publisher's peer review policy. The author has not responded to correspondence regarding this retraction

1 Jiujiang University, Jiujiang 332005, China 